\title{
Unbiased Stereological Estimation of the Spiral Ligament and Stria Vascularis Volumes in Aging and Ménière's Disease Using Archival Human Temporal Bones
}

\author{
Gail Ishiyama, ${ }^{1}$ Joshua Tokita, ${ }^{2}$ Ivan Lopez, ${ }^{3}$ Yong Tang, ${ }^{4,5}$ and AkIra Ishiyama ${ }^{3,6}$ \\ ${ }^{1}$ Neurology Department, David Geffen School of Medicine, UCLA, Los Angeles, CA 90095, USA \\ ${ }^{2}$ College of Medicine, University of Illinois at Chicago, Chicago, IL 60612, USA \\ ${ }^{3}$ Surgery Department, Division of Head and Neck, David Geffen School of Medicine at UCLA, Los Angeles, CA 90095, USA \\ ${ }^{4}$ Department of Histology and Embryology, Chongqing University of Medical Sciences, Chongqing, China \\ ${ }^{5}$ Institute for Basic Medical Science, Chongqing University of Medical Sciences, Chongqing, China \\ ${ }^{6}$ UCLA School of Medicine, 10833 Le Conte Avenue, Los Angeles, CA 90095, USA
}

Received: 12 June 2006; Accepted: 1 October 2006; Online publication: 8 December 2006

\begin{abstract}
The present study applies the unbiased stereological technique-Cavalieri principle to measure the volumes of the stria vascularis (SV) and the spiral ligament (SL) using postmortem archival human temporal bones from normal young and older subjects and subjects with Ménière's disease. Normative data was obtained from subjects without ages ranging from 15 to 84 years old who had no history of audiovestibular disease $(N=25)$. For comparison purposes, the normative specimens were divided into three groups: group $1(n=8)$ had ages ranging from 15 to 38 years old, average age $=23.9$; group $2(n=8)$ had ages ranging from 51 to 59 years old, average age $=55.1$; group $3(n=9)$ had ages ranging from 64 to 84 years old, average age $=74.3$. The average SV volume of group $3\left(0.479 \mathrm{~mm}^{3}\right)$ was significantly lower than that of group $1\left(0.705 \mathrm{~mm}^{3}\right)(p<0.0005)$ and was significantly lower than that of group 2 $\left(0.603 \mathrm{~mm}^{3}\right)(p=0.01)$. The average SL volume of group $3\left(8.42 \mathrm{~mm}^{3}\right)$ was significantly lower than that of group $1\left(9.54 \mathrm{~mm}^{3}\right)(p<0.05)$, but was not significantly lower than that of group $2\left(8.58 \mathrm{~mm}^{3}\right)$. Five subjects with Ménière's disease, confirmed by histopathological examination (ages ranging from 63
\end{abstract}

Correspondence to: Akira Ishiyama - UCLA School of Medicine • 10833 Le Conte Avenue, Los Angeles, CA 90095, USA. Telephone: +1-310-8255331; email: ishiyama@ucla.edu to 91 years old, average age $=73.4)$, were studied. The average SV volume in Ménière's subjects $\left(0.378 \mathrm{~mm}^{3}\right)$ was significantly lower than age-matched controls $(p<0.05)$. The average SL volume in Ménière's subjects $\left(7.01 \mathrm{~mm}^{3}\right)$ was also significantly lower than age-matched controls $(p<0.05)$. The SV and SL volumes were unaffected by gender. The present study demonstrates for the first time the use of the unbiased stereological technique-Cavalieri principle-as a reliable and efficient method to obtain volumetric estimates of the SV and the SL by using archival human temporal bone specimens.

Keywords: stria vascularis, spiral ligament, archival human temporal bone, aging, Ménière's disease, volume estimation, unbiased stereology

\section{INTRODUCTION}

The spiral ligament (SL) is a complex structure of fibrocytes, intercellular substances, and blood vessels, which lines the sulcus of the cochlear duct. The inner surface of the SL, extending from the spiral prominence to Reissner's membrane, is lined with a collection of pigmented cells, the stria vascularis (SV) (Schuknecht 1993). The lateral wall of the cochlea encloses numerous fibrocytes that have been differentiated into five cell types (Spicer and Schulte 
1996). Microscopic preparations show that the stria is dense with numerous capillaries passing mainly in the longitudinal direction. Three types of cells are identified: the marginal cells on the endolymphatic surface, the intermediate cells, and the basal cells adjacent to the SL (Schuknecht 1993). Spicer and Schulte $(1991,1996)$ defined the fibrocytes of the SL of the gerbil cochlear, and divided them into five types (I, II, III, IV, and V) according to the cytochemical features related to ion transport activity. Using the chinchilla model, gap junctions have been demonstrated between the fibrocytes of the SL, and between the fibrocytes and the strial basal cells (Reale et al. 1975). Bagger-Sjöbäck et al. (1987) used freeze fracturing of the human SV to elucidate the ultrastructure, and described tight junctions separating the marginal cells from the endolymphatic space, and also separating the basal cells from the SL.

The SV and the SL are involved in the maintenance of the homeostasis of endolymph volume and in the generation of the positive endocochlear potential (Spicer and Schulte 1996; Kikuchi et al. 2000). It has been theorized that the SL serves as the main pathway for sodium and potassium ion transport between the scala tympani, the scala vestibuli, and the scala media (Kikuchi et al. 2000; Weber et al. 2001), maintaining the $+80 \mathrm{mV}$ endococochlear potential necessary for the depolarization of hair cells. Potassium ions are theorized to be taken up by NaKATPase and $\mathrm{NaKCl}$ cotransporters in the type II fibrocytes of the SL. Potassium ions may then pass through the tight junctions of the strial basal cells via gap junctions connecting the type I fibrocytes and intermediate strial cells. The ions are then picked up by the marginal strial cells that then release them into the endolymph (Kikuchi et al. 2000). Atrophy or pathology of the SV and SL has also been implicated in several inner ear pathologies including otosclerosis, Ménière's disease, and hearing loss associated with aging.

Age-related hearing loss is the most common form of hearing loss, and it is likely the most prevalent neurodegenerative disease of aging. It has been noted that archival human temporal bones from older subjects demonstrated an age-related degeneration of the SL, with atrophy and diminished fibrocytic density and areas of acellularity (Schuknecht 1993; Wright and Schuknecht 1972). In the early human temporal bone studies, age-related strial atrophy was associated with sclerotic changes in the vasculature (Saxen 1952). The role of SL pathology and SV pathology in age-related hearing loss remains controversial (Ohlemiller 2004). Many models of agerelated hearing loss propose that the initial insult occurs in the SL or the SV (Spicer and Schulte 2002). Previous morphometric studies on the human SL used analysis in one or two dimensions. Wever (1949) reported the cross-sectional area of the basal and apical turns of the SL to be 0.543 and $0.042 \mathrm{~mm}^{2}$, respectively. Oka (1984) reported the width of the SV of the basal turn to be $0.34 \mathrm{~mm}$ in adults and $0.36 \mathrm{~mm}$ in newborns. In the apical turn, he reported values of 0.27 and $0.31 \mathrm{~mm}$ in adults and newborns, respectively. However, morphometric analysis in two dimensions can be subject to bias secondary to differential planes of section, and thus volumetric data are preferable to analysis in one or two dimensions.

Ménière's syndrome is characterized by recurrent spells of spontaneous vertigo, tinnitus, and hearing loss, first described in 1861 by Ménière. In temporal bone histopathological studies, subjects with a history of the classical symptoms of Ménière's disease had endolymphatic hydrops, a ballooning distension of the endolymphatic system in one or both ears (Yamakawa 1938; Hallpike and Cairns 1938; Schuknecht 1993; Rauch et al. 1989; Merchant et al. 2005). However, it has been noted that many cases of idiopathic and secondary hydrops occur in subjects with no history of the classical symptoms of Ménière's disease (Rauch et al. 1989; Merchant et al. 2005). It was theorized that endolymphatic hydrops is the result of an alteration of fluid homeostasis mechanisms in the inner ear secondary to a disruption of enzymes within the SL, and that the primary mechanism that produced the symptoms of Ménière's disease is SL dysfunction. Thus, hydrops may be a marker for Ménière's disease, with the primary pathology occurring in the SL or the SV. Previous studies have yielded mixed results regarding the association of atrophy of the SL or SV with Ménière's disease, and one study reported no evidence of SL atrophy in Ménière's disease, using length and width measurements of the SL in archival human temporal bones (Harris and Keithley 2002).

Previous studies investigated the relationship between atrophy of the SV and SL and inner ear pathologies, based on two-dimensional measurements of the SV and the SL through the midmodiolar section (Doherty and Linthicum 2004; Kwok and Nadol 1989; Nelson and Hinojosa 2003; Pauler et al. 1988), two-dimensional measurements of specific cell loss (Kusunoki et al. 2004), or qualitative assessments (Schuknecht 1993). The present study uses the unbiased stereological technique, Cavalieri principle, to estimate the volume of the SV and the SL in archival human temporal bone specimens. Our laboratory has successfully applied unbiased stereological techniques by using postmortem human temporal bone specimens to obtain type I and type II hair cell counts in the human vestibular endorgans (Lopez et al. 2005b; Gopen et al. 2003), vestibular ganglion neuronal number in aminoglycoside ototoxicity (Ishiyama et al. 2005) and in aging (Ishiyama 
et al. 2004; Park et al. 2001), normative spiral ganglion number (Ishiyama et al. 2001), and vestibular nerve fiber counts and diameter distribution (Lopez et al. 2005a). Previous studies have applied unbiased stereology to obtain cell volume density estimates of SV in the chinchilla by using a pointcounting technique (Santi and Lakhani 1983; Santi and Muchow 1979). However, to our knowledge, there are no previous studies that have used the unbiased stereological techniques to estimate the volume of the SV or the SL in human subjects.

\section{MATERIALS}

\section{Human materials}

All specimens were from the University of California Los Angeles Archival Temporal Bone Collection. All donors had consented to the use of temporal bones for research; signed consent forms accompanied each specimen. Details regarding age and sex of each subject are presented in Tables 1, 2, and 3. For the normative specimens, autopsy and medical reports were reviewed, and the history demonstrated no treatments that affect the audiovestibular system.

\begin{tabular}{|c|c|c|c|c|c|c|}
\hline \multicolumn{7}{|c|}{ TABLE 1} \\
\hline \multicolumn{7}{|c|}{$\begin{array}{l}\text { Volume of spiral ligament and stria vascularis in normal } \\
\text { individuals }\end{array}$} \\
\hline Subject & Sex & Age & $S L\left(\mathrm{~mm}^{3}\right)$ & $C E$ & $S V\left(\mathrm{~mm}^{3}\right)$ & $C E$ \\
\hline 1 & $M$ & 15 & 8.88 & 0.059 & 0.881 & 0.089 \\
\hline 2 & M & 15 & 9.01 & 0.057 & 0.820 & 0.057 \\
\hline 3 & $\mathrm{~F}$ & 20 & 11.74 & 0.049 & 0.796 & 0.072 \\
\hline 4 & M & 21 & 10.02 & 0.072 & 0.640 & 0.077 \\
\hline 5 & $\mathrm{~F}$ & 26 & 10.18 & 0.062 & 0.635 & 0.061 \\
\hline 6 & $\mathrm{~F}$ & 27 & 9.09 & 0.107 & 0.567 & 0.071 \\
\hline 7 & $\mathrm{~F}$ & 29 & 9.04 & 0.087 & 0.657 & 0.091 \\
\hline 8 & $M$ & 38 & 8.35 & 0.064 & 0.641 & 0.072 \\
\hline 9 & $\mathrm{~F}$ & 51 & 7.14 & 0.061 & 0.581 & 0.107 \\
\hline 10 & M & 52 & 8.69 & 0.067 & 0.769 & 0.118 \\
\hline 11 & M & 52 & 8.64 & 0.067 & 0.825 & 0.100 \\
\hline 12 & M & 55 & 9.63 & 0.069 & 0.690 & 0.073 \\
\hline 13 & M & 56 & 8.51 & 0.083 & 0.579 & 0.071 \\
\hline 14 & $\mathrm{~F}$ & 57 & 8.77 & 0.065 & 0.659 & 0.103 \\
\hline 15 & $\mathrm{~F}$ & 59 & 8.96 & 0.079 & 0.473 & 0.089 \\
\hline 16 & $\mathrm{~F}$ & 59 & 8.31 & 0.070 & 0.446 & 0.059 \\
\hline 17 & $M$ & 64 & 7.89 & 0.037 & 0.516 & 0.096 \\
\hline 18 & $M$ & 65 & 6.97 & 0.078 & 0.500 & 0.127 \\
\hline 19 & $M$ & 66 & 8.65 & 0.071 & 0.468 & 0.112 \\
\hline 20 & $\mathrm{~F}$ & 72 & 7.96 & 0.061 & 0.511 & 0.059 \\
\hline 21 & $M$ & 74 & 9.50 & 0.068 & 0.397 & 0.083 \\
\hline $22^{a}$ & $M$ & 80 & 9.03 & 0.044 & NA & NA \\
\hline 23 & $\mathrm{~F}$ & 80 & 7.76 & 0.084 & 0.381 & 0.012 \\
\hline 24 & $\mathrm{~F}$ & 84 & 9.31 & 0.045 & 0.414 & 0.075 \\
\hline 25 & $\mathrm{~F}$ & 84 & 8.75 & 0.123 & 0.644 & 0.082 \\
\hline Mean & & & & 0.072 & & 0.085 \\
\hline
\end{tabular}

$\mathrm{SL}$, spiral ligament; SV, stria vascularis; $\mathrm{CE}$, coefficient of error.

${ }^{a}$ Volume of stria vascularis was not measured in this sample due to poor preservation.

\section{Equipment}

Equipment setup was identical to that described in a previous study by Lopez et al. (2005a). The volume was estimated with unbiased stereological techniques using Stereo Investigator version 5.0 (MicroBrightField Inc., Colchester, VT, USA) on a Windows-based personal computer. The personal computer was connected to a Cohu (San Diego, CA, USA) digital camera mounted on a Nikon (Tokyo, Japan) Optiphot microscope. Stage movement was motorized and computer-controlled by an LEP Bio-point (Hawthorne, NY, USA) stage controller allowing for very precise movements along the $x$ - and $y$-axes. Images were captured on screen by using a Nikon $4 \times$ lens with a numerical aperture of 0.1 .

\section{METHODS}

\section{Selection of control group}

A catalog was made containing all temporal bone samples from patients who did not have a history of audiovestibular illness. Stereo Investigator random number generator function was used to randomly select four samples from male donors in the 0- to 39-year-old, 40- to 59-year-old, and 60+-year-old age brackets. The process was repeated to select samples for female donors. Details regarding the age and sex of subjects are presented in Tables 1, 2, and 3.

\section{Selection of samples from patients with Ménière's disease}

All specimens from subjects suffering from Ménière's disease in the UCLA archival human temporal bone collection were analyzed. Details regarding the age and sex of subjects are presented in Table 3 . Histopathological analysis confirmed the presence of endolymphatic hydrops and clinical data was consistent with the AAO-HNS criteria for Ménière's disease (Committee on Hearing and Equilibrium 1995). Age of subjects (two females, three males) ranged from 63 to 91 years (average $=73.4$ years) .

\section{Selection of slides for volume estimation}

Following removal at autopsy, the temporal bones were fixed in formalin solution, decalcified with EDTA, embedded in celloidin, and sectioned in the axial (horizontal) plane at $20-\mu \mathrm{m}$ thickness. Every 10 th section was stained with hematoxylin and eosin. All of the stained sections containing the SL or the SV were isolated and organized in the order in which they were sectioned. The random number generator was used to select one of the first three sections to 
TABLE 2

\begin{tabular}{|c|c|c|c|c|c|}
\hline \multicolumn{6}{|c|}{ Average volume of spiral ligament and stria vascularis in age groups } \\
\hline Age group (years) & $\begin{array}{l}\text { Number } \\
\text { of specimens }\end{array}$ & $\begin{array}{l}\text { Age range } \\
\text { (years) }\end{array}$ & $\begin{array}{l}\text { Average age } \\
\text { (years) }\end{array}$ & $\begin{array}{l}\text { Average } S L \\
\left(\mathrm{~mm}^{3}\right)\end{array}$ & $\begin{array}{l}\text { Average SV } \\
\left(\mathrm{mm}^{3}\right)\end{array}$ \\
\hline Less than 40 & 8 & $15-38$ & $23.9 \pm 7$ & $9.54 \pm 1$ & $0.705 \pm 0.11$ \\
\hline $50 \mathrm{~s}$ & 8 & $51-59$ & $55.1 \pm 3.1$ & $8.58 \pm 0.7$ & $0.630 \pm 0.13$ \\
\hline Above 60 & 9 & $64-84$ & $74.3 \pm 8$ & $8.42 \pm 0.8$ & $0.479 \pm 0.08$ \\
\hline
\end{tabular}

$\mathrm{SL}$, spiral ligament; SV, stria vascularis; \pm , standard deviation.

analyze. After the first section was randomly selected, every third section was selected for analysis. For example, if a series of sections contained 36 slides, the computer would randomly choose one of the first three sections to analyze. If the computer were to randomly choose section 2, the analysis of the temporal bone would be performed on sections 2, $5,8,11, \ldots, 35$. In this way, one of every 30 serial sections was analyzed. Because we collected pseudorandomly generated sections (every third section after a randomly chosen starting section) and because the placement of the grid over the images was randomly conducted by the computer, the results are unbiased.

\section{Theoretical background of the Cavalieri stereological method}

The Cavalieri method is named after the Italian mathematician Buonaventura Cavalieri (Cavalieri, reprinted in 1966), a pupil of Galileo. The method has been refined and modified in a series of applications involving invasive and noninvasive scanning (Gundersen and Jensen 1987; Mayhew and Olsen 1991; Pakkenberg et al. 1989). According to Cavalieri principle, the volume of arbitrarily complex structures can be estimated from the sum of parallel areas separated by a known distance, provided that the set of sections is positioned at random with respect to the chosen axis (Gundersen and Jensen 1987). Profile areas are most efficiently estimated by point counting (Gundersen et al. 1981; Mathieu et al.
1981). The Cavalieri method consists of the following steps:

1. Scan or physically cut the object in a series of parallel planes a distance $\mathrm{T}$ apart, the first plane starting randomly in the interval 0 to $\mathrm{T}$.

2. The sectional area of the object cut can be efficiently estimated with the point-counting method (Gundersen et al. 1981; Mathieu et al. 1981). The point-counting method consists of randomly (conducted by computer) superimposing onto each section a test lattice overlay bearing a systematic arrangement of test points. Counting points that fall on the profiles of the object provides an unbiased estimate of the areas of the object profiles. If the area equivalent of each test point is known, then the total area $\left(\sum \mathrm{A}\right)$ of the object profiles on all slices is estimated from the total number of test points, $\sum \mathrm{P}$, using

$$
\sum A=a(p) \sum P
$$

where $a(p)$ represents the area associated with each test point.

3. From these area estimates with the point-counting method and the mean distance between sections, $\mathrm{T}$, the unbiased volume $(\mathrm{V})$ estimator, becomes

$$
V=T \sum A=T a(p) \sum P=T a(p)\left(P_{1}+P_{2}+\cdots+P_{m}\right)
$$

where $P_{1}, P_{2}, \ldots, P_{m}$ denote the points counted in $\mathrm{m}$ sections. Note that this simple volume estimator

\begin{tabular}{|c|c|c|c|c|c|c|}
\hline \multicolumn{7}{|c|}{ Volume of spiral ligament and stria vascularis in individuals with Meniere's disease } \\
\hline Subject & Sex & $\begin{array}{l}\text { Age } \\
\text { (years) }\end{array}$ & $\begin{array}{l}S L \\
\left(\mathrm{~mm}^{3}\right)\end{array}$ & $C E$ & $\begin{array}{l}S V \\
\left(\mathrm{~mm}^{3}\right)\end{array}$ & $C E$ \\
\hline 40 & $\mathrm{~F}$ & 63 & 6.17 & 0.067 & 0.294 & 0.113 \\
\hline 41 & M & 66 & 7.56 & 0.063 & 0.421 & 0.139 \\
\hline 42 & M & 72 & 8.40 & 0.038 & 0.421 & 0.108 \\
\hline 43 & $M$ & 75 & 6.16 & 0.088 & 0.349 & 0.114 \\
\hline 44 & $\mathrm{~F}$ & 91 & 6.74 & 0.083 & 0.405 & 0.089 \\
\hline Average & & $73.4 \pm 11$ & $7.01 \pm 1$ & 0.070 & $0.378 \pm 0.05$ & 0.114 \\
\hline
\end{tabular}

TABLE 3

$\mathrm{SL}$, spiral ligament; SV, stria vascularis; $\mathrm{CE}$, coefficient of error; \pm , standard deviation. 
requires absolutely no assumptions about the shape or spatial arrangement of the object itself.

\section{Methodology of volume estimation using the Cavalieri technique}

Volume measurements were carried out by using the "contour" and "Cavalieri estimator probe" of the Stereo Investigator software package. Each section was mounted on a Nikon Optiphot light microscope and viewed at $4 \times$. A Cohu digital camera was used to photograph all areas of the slide where either the SL or SV was present. Once the desired area had been captured, the SL and the SV were outlined. The Cavalieri probe (Stereo Investigator), a series of grid points, was then randomly placed by the software over the photograph taken with the Optiphot camera. The grid points used in the probe marked the intersection points on a $120 \times 120 \mu \mathrm{m}$ grid that was oriented at a computer-generated, random angle between $0^{\circ}$ and $45^{\circ}$ (Fig. 1). Each grid point thus represents an area of $14,400 \mu \mathrm{m}^{2}$. The size of the grid was chosen such that, on average, 200-500 points would be counted per specimen. With the grid in place over the SL and SV contours, the grid points lying within the contour were selected. If the grid points fell onto the outline, the points were selected if their right upper corner was located inside the outline. The program was used to estimate the area of the contours based on the number of selected grid points. The associated volume was calculated by multiplying the area by 600 , which accounts for the $20-\mu \mathrm{m}$ thickness of each section and the sampling of every 30 sections. This process was repeated on each of the selected samples with the computer totaling the volume associated with each section in order to yield a final volume.

\section{Designation of age groups}

For comparison purposes, subjects with no history of audiovestibular illnesses were divided into three

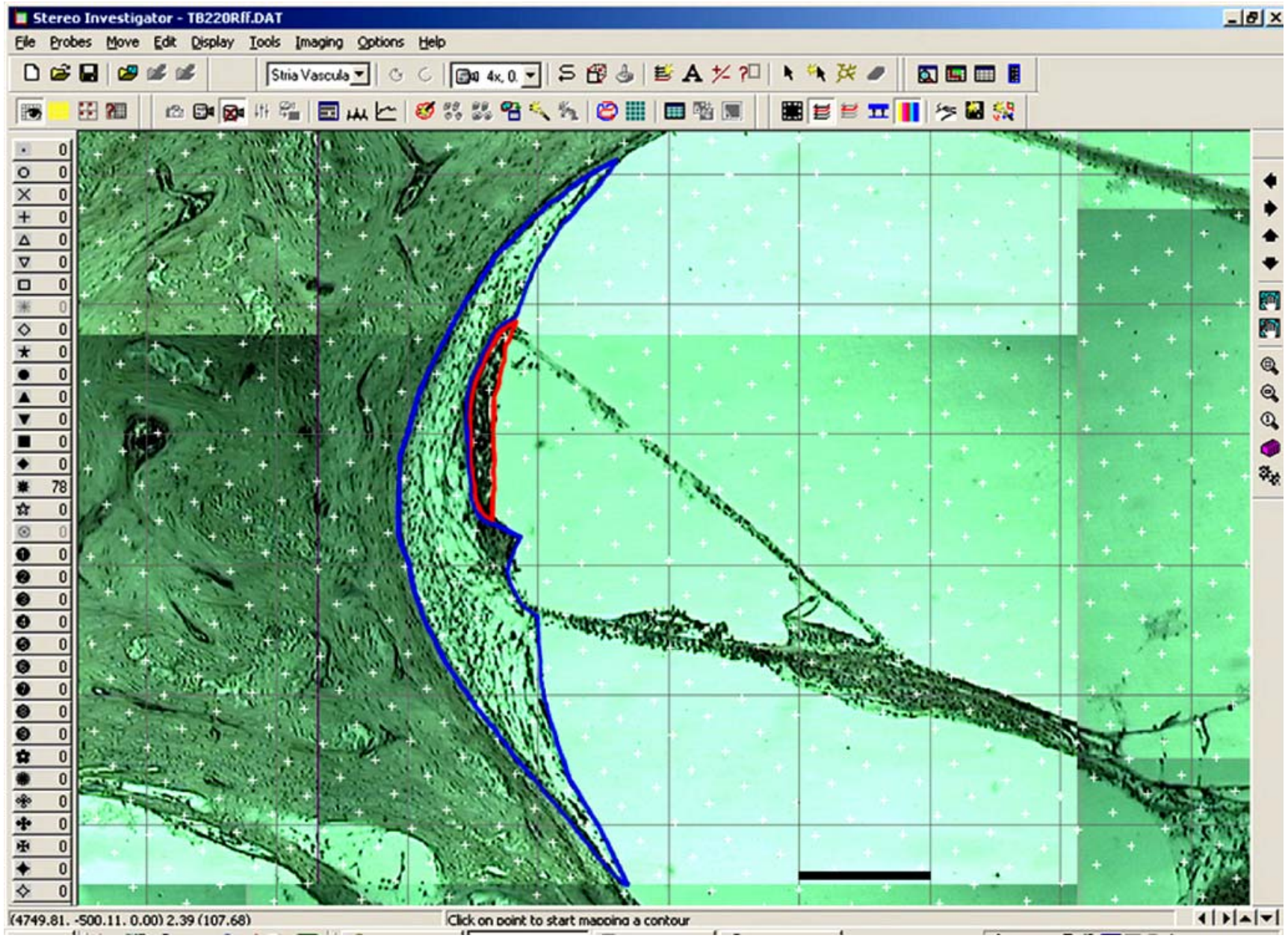

FIG 1. Each region of the slide that shows either the spiral ligament or stria vascularis is photographed so that the entire region of interest can be examined on one screen. The entire region of interest is captured, then the spiral ligament and stria vascularis are outlined, and a randomly oriented grid is placed over the contours. The area estimation is based on the number of grid points that falls within the contour. Scale bar (in black): $150 \mu \mathrm{m}$. 


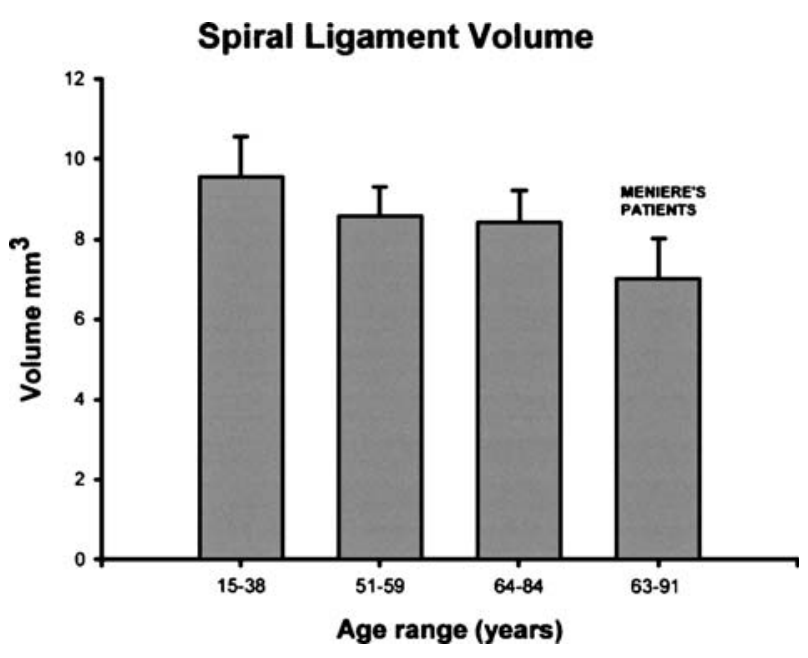

FIG 2. Histograms of the spiral ligament volume in each age group (including Meniere's disease patients). They represent the average and the standard error of the mean for each value.

groups. Specimens in group $1(n=8)$ are from subjects in the young adult range (range $=15-38$ years, average $=23.9)$. Specimens in group $2(n=8)$ are from subjects in their 50s (range $=51-59$ years, average $=55.1)$. Specimens in group $3(n=9)$ are from subjects who are in their 60 s or older (range $=64$ 84 years, average $=74.3$ ).

\section{Statistics}

Unpaired, one-tailed $t$-tests for samples with unequal variances were used to determine statistical significance. The volumes of SL and SV for the group with Ménière's disease (average age $=73.4$ years) was compared with those from group 3 (average age $=74.3$ years). Comparisons between groups with a $p$ value of less than 0.05 were considered to be statistically significant.

Although the results obtained by the present technique are statistically unbiased, these results represent estimates, not absolute determinations of the volumes. These estimates have a certain degree of precision that is related to the amount of sampling performed. The precision of these estimates is represented by the inverse of the coefficient of error (CE) of each individual estimate. The usual formula for estimating CE (standard error of the mean divided by the mean) is valid for independently derived observations. The present design was based on systematic random sampling design that is an unbiased sampling design and is more efficient than independent random sampling design (Gundersen and Jensen 1987). Therefore, the CE for the present design cannot be calculated in the usual manner. The CE was calculated according to Gundersen et al. (1999).

\section{RESULTS}

Spiral ligament volume estimate in subjects without a history of audiovestibular illness

Table 1 shows the volume estimates of the SL and the $\mathrm{SV}$ in individual specimens from subjects who had no history of audiovestibular diseases. Table 2 and Figure 2 show the averages for each age group. This study found an average SL volume of $9.54 \mathrm{~mm}^{3}$ in group $1,8.58 \mathrm{~mm}^{3}$ in group 2, and $8.42 \mathrm{~mm}^{3}$ in group 3. The average SL volume in group 2 was $10.0 \%$ lower than that in group $1 \quad(p=0.03)$. The average SL volume in group 3 was $11.7 \%$ lower than that in group $1 \quad(p=0.02)$. There was no significant difference in average volume of SL between groups 2 and 3 (Figure 2).

Stria vascularis volume estimate in subjects without a history of audiovestibular illness

This study found an average SV volume of $0.705 \mathrm{~mm}^{3}$ in group 1, $0.603 \mathrm{~mm}^{3}$ in group 2, and $0.479 \mathrm{~mm}^{3}$ in group 3. The average SV volume in group 2 was $10.6 \%$ less than that in group 1, but was not significantly different (Table 2, Fig. 3). The average volume of SV in group 3 was $32.0 \%$ less than that in group $1 \quad(p=0.0003)$, and $24.0 \%$ less than that in group $2(p=0.01)$.

Spiral ligament and stria vascularis volume estimate in subjects with a history

of Ménière's disease

Patients who had a history of Ménière's disease (age range $=63-91$ years, average $=73.4)$ had an SV volume

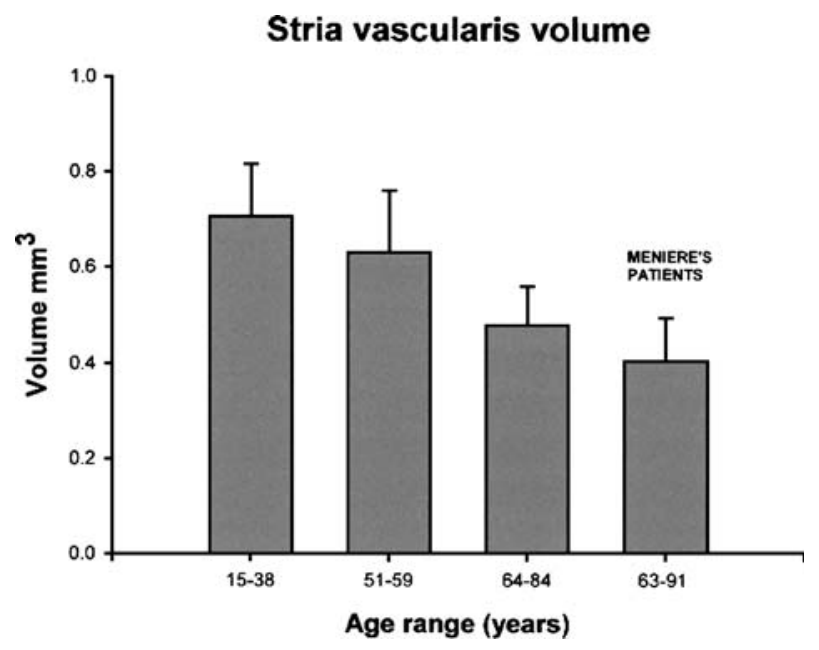

FIG 3. Histograms of the stria vascularis volume in each age group (including Meniere's disease patients). They represent the average and the standard error of the mean for each value. 
of $0.367 \mathrm{~mm}^{3}$, which was significantly lower compared to that of normal subjects in the same age group (group 3: $0.479 \mathrm{~mm}^{3}, p=0.01$ ) (Table 3). Subjects with Ménière's disease had an average SL volume of $6.86 \mathrm{~mm}^{3}$, which is significantly lower compared to that of normal subjects in the same age group (group 3: $8.42 \mathrm{~mm}^{3}, \mathrm{p}=0.01$ ) (Table 3, Fig. 2). Compared with their counterparts in the same age group (group $3)$, those with Ménière's disease had a $16.7 \%$ decreased SL volume and a $21.1 \%$ decreased SV volume (Table 3, Fig. 3).

No difference in spiral ligament and stria vascularis volume in males vs. females

There were no significant differences of the volume of the SL and SV between males and females.

\section{Mean CE demonstrates acceptably precise estimates}

The mean CE for the volume estimates of SL and for the volume estimate of SV in normal individuals was 0.072 and 0.085 , respectively (Table 1 ). The mean CE for volume estimates of SL and SV in individuals who have Ménière's disease was 0.070 and 0.114 , respectively (Table 3). These results indicate that the sampling design yielded acceptably precise estimations of the volumes of SL and SV.

\section{DISCUSSION}

In the present study, the design-based stereological Cavalieri method was applied to obtain unbiased estimates of the SV and SL volume using archival human temporal bone specimens from 15- to 84-yearold subjects without a history of audiovestibular illness, and from subjects with Ménière's disease. To our knowledge, this is the first study to apply designbased stereological techniques to obtain estimates of the human SV and SL volumes.

Stria vascularis volumetric data is in alignment with previous studies

Nelson and Hinojosa (2003) used reconstruction in two dimensions and a correction based on an estimation of the angle of sectioning from the appearance of the specimen to obtain an SV volume ranging from 0.3054 to $0.4821 \mathrm{~mm}^{3} \quad\left(\right.$ mean $\left.=0.4097 \mathrm{~mm}^{3}\right)$. The authors also used a method described by Pauler et al. (1988) to obtain cross-sectional areas of the SV, and reported similar values. Our estimates of SV volume obtained using unbiased stereology are in agreement with the results of Nelson and Hinojosa. However, in our study the estimated strial volume of the younger adults was significantly higher than that in Nelson and Hinojosa. In the present study, the average SV volume of group 1 (average age $=23.9$ years) was $0.705 \mathrm{~mm}^{3}$, which is higher than the corresponding SV volumes of 0.456 and $0.482 \mathrm{~mm}^{3}$, for a 9- and a 20-year-old subject in Nelson and Hinojosa's study. Differences may be attributable to inaccurate accounting for the plane of section, differences in temporal bone processing, interindividual differences, or methodology.

There is a significant loss of volume in SV and SL with increasing age, in agreement with prior studies, and the onset of spiral ligament atrophy appears to occur earlier than that of the stria

In the present study, the average volume of the SL in normative controls was significantly lower by $10 \%$ in subjects in their 50s compared to the young adult age group. However, there was no significant further decrement in SL volume in adults older than 60 years compared to those who are in their 50s. This suggests that the loss in SL volume starts when patients are in their $50 \mathrm{~s}$ and then begins to plateau. The onset of stria atrophy was noted after subjects reach their $60 \mathrm{~s}$ (group 3), with a $32 \%$ loss of volume compared with the younger adult group 1 and a $24 \%$ volume loss compared with those in their 50s (group 2). The onset of strial atrophy appears to be delayed by a decade (starting in the 60s) as compared with SL atrophy, and the degree of SV atrophy is relatively greater than that in the SL. Further studies covering a greater number of subjects in the younger age groups are needed to investigate the pattern of agerelated degeneration of the SV and SL.

Previous studies on human temporal bone specimens have reported age-related strial and spiral ligament atrophy. A patchy loss of SL fibrocytes was noted at the basilar crest in older subjects (Wright and Schuknecht 1972). Kusunoki et al. (2004) reported a significant age-related decrease in the SV area at the lower basal turn by measuring the crosssectional area of the SV in perpendicular appearing specimens. In alignment with the results of Kusunoki et al. (2004), the present study demonstrates a decreasing SV volume with increasing age for individuals who are past their 50s. To evaluate age-related SL atrophy, Kusunoki used a qualitative rating system, developed by Hequembourg and Liberman (2001), and described a prominent loss of SL fibrocytes in the basilar crest in all age groups above 9 years old, in comparison with the $0-2$ years age group. Kusunoki et al. (2004) also proposed that the onset of strial atrophy occurred later than that of the 
SL, and our study findings are in agreement, as noted above. There is evidence for cell migration from underlying SL cells to replace the loss of apoptotic strial cells (Dunaway et al. 2003). Thus, if the initial pathology occurs in the SL, then the SL precursor cells cannot intervene and replace the apoptotic SV marginal cells. In the C57BL16 mouse model, type IV fibrocytes of the SL are the first cell type to demonstrate significant age-related degeneration (Hequembourg and Liberman 2001). Doherty and Linthicum (2004) noted a decrease in NaKATPase staining in the SV in the presence of SL hyalinization in cochlear otosclerosis, and proposed an interdependence of the stria and the spiral ligament. Thus, the onset of spiral ligament atrophy appears to occur at an earlier age than that of the SV, and there is likely interdependence of the structures.

While the etiology of age-related cellular changes in the SL and SV remains unknown, the cumulative effects of acoustic trauma and exposure to ototoxic compounds have been proposed (Keithley et al. 2001). A loss of strial capillaries has been reported to correlate with regional strial atrophy in human (Johnsson and Hawkins 1972) and in quiet-aged gerbils (Gratton and Schulte 1995; Gratton et al. 1997). Strial marginal cells may be exceptionally vulnerable to aging because of the high volume density of mitochondria, and the resultant high potential for generating reactive cytotoxic oxygen radicals. Strial atrophy has been correlated with diminished function of the cochlea in animal models and with reduced immunostaining for NaKATPase (Schulte and Schmiedt 1992; Spicer et al. 1997). A diminished diffusion of potassium ions through the strial marginal cells may cause degeneration of NaKATPase containing type II, IV, and V fibrocytes (Spicer and Schulte 2002). Researchers argue which one is primarily involved: the SL or the SV. Ichimiya et al. (2000) reported SL connexin 26 expression diminishes earlier than immunohistochemical changes in SV, concluding that biochemical changes in the SL occur first. In contrast, Spicer et al. (1997) concluded that the primary pathology occurs in the SV. The present study provides quantitative confirmation of previous studies reporting degeneration of SL and SV with aging, and further studies on the etiology and initial localization of neurodegenerative changes in the cochlea may lead to targeted therapeutic interventions.

\section{There is significant decrement in SL and SV} volume in Ménière's disease

Our study demonstrates that individuals who have Ménière's disease have decreased SL and SV volume in comparison to age-matched normative controls.
The average volume of the SL in individuals who have Ménière's disease was decreased by $16.7 \%$ compared with the average volume of the SL in agematched normal subjects. The average volume of SV in individuals with Ménière's disease was decreased by $21.1 \%$ compared with that in age-matched normal subjects. Our results provide unbiased estimates to confirm previous archival human temporal bone studies that reported histopathological atrophy of the SV associated with Ménière's disease (Schuknecht 1993; Nadol et al. 1995). Our results also confirm those of Vasama and Linthicum (1999), who reported that Ménière's disease was associated with strial atrophy (61\% of normative age-matched control). However, they also reported a normal SL area in Ménière's disease-affected individuals (Vasama and Linthicum 1999). Vernick (1983) reported that strial atrophy, assessed by cross sections, occurred in eight temporal bones from five subjects with endolymphatic hydrops. Nadol et al. (1995) reported ultrastructural lesions of the SL in archival human temporal bone studies on Ménière's disease.

Previous studies suggest several possible etiologies for Ménière's disease. Earlier studies by Kitahara had suggested that endolymphatic hydrops observed in Ménière's disease may be attributable to underabsoprtion or overproduction of endolymph (Kitahara et al. 1982; Kimura 1982). However, endolymphatic hydrops is not necessarily associated with the clinical signs of Ménière's disease in all cases, and hydrops may be a histological marker for Ménière's disease rather than the cause of symptoms (Rauch et al. 1989; Merchant et al. 2005). Shinomori et al. (2001) demonstrated that obliteration of the endolymphatic duct resulted in a disruption of enzymes within the SL, and importantly the disruption of enzymes occurred before the development of hydrops. Therefore, it has been proposed that the primary cause of Ménière's disease may be a dysfunction of the SL or the SV. Archival human temporal bone studies demonstrated that strial atrophy, as measured by cross-sectional area morphometric measures, correlated with a decreased number of vessels in the SV in patients who had Ménière's disease (Masutani et al. 1992) and in guinea pig endolymphatic hydrops models (Yazawa et al. 1998). Thus, the SV atrophy in Ménière's disease may reflect a pathophysiology that may be related to decreased vascularity of the SL and SV structures. In the present study, there was atrophy of both the SV and the SL in Ménière's disease, as compared to age-matched controls, in agreement with prior studies, and also in alignment with current theories regarding the primary pathology being dysfunction of the SL or SV, rather than endolymphatic hydrops itself. 


\section{CONCLUSION}

The current study demonstrates the application of unbiased stereology, Cavalieri principle, using archival human temporal bones to obtain estimates of SV and SL volumes in individuals of varying ages with no history of audiovestibular pathology, and in individuals with Ménière's disease. SV volume was significantly reduced in individuals who are in their $60 \mathrm{~s}$ and older compared with younger individuals (in their 50s and younger). SL volume was significantly reduced, starting when subjects were in the $50 \mathrm{~s}$, and subsequently plateaued. Ménière's disease is associated with significantly decreased SV and SL volume. In general, the results confirm previous morphometric reports that aging and Ménière's disease are associated with atrophy of the SV and the SL. Unbiased stereology is a powerful tool that can be applied to the archival human temporal bone to obtain true volumetric analyses of structures of interest.

\section{ACKNOWLEDGEMENT}

This study was supported by National Institutes of Health grants DC 005028-01, DC 00140-02, DC 05187-01, and AG 09693.

\section{REFERENCES}

Bagger-Sjöbäck D, Engström B, Steinholtz L, Hillerdal M. Freeze fracturing of the human stria vascularis. Acta Otolaryngol. (Stokh.) 103:64-72, 1987.

Cavalieri B. Geometria Invisibilibus Continuorum. Bononiae: Typis Clementis Ferronij; 1635. Reprinted in 1966 as Geometria Degli Indivisibli. Unione Tipografico Editrice, Torino.

Committee on Hearing and Equilibrium. Meniere's disease; criteria for diagnosis and evaluation of therapy for reporting. Otolaryngol. Head Neck Surg. 113:181-185, 1995.

DOHERTy JK, Linthicum FH JR. Spiral ligament and stria vascularis changes in cochlear otosclerosis: effect on hearing level. Otol. Neurotol. 25(4):457-64, 2004.

Dunaway G, Mhaskar Y, Armour G, Whitworth C, Rybak L. Migration of cochlear lateral wall cells. Hear. Res. 177(1-2):111, 2003.

Gopen Q, Lopez I, Ishiyama G, Baloh RW, Ishiyama A. Unbiased stereologic type I and type II hair cell counts in human utricular macula. Laryngoscope 113(7):1132-1138, 2003.

Gratton MA, Schulte BA. Alterations in microvasculature are associated with atrophy of the stria vascularis in quiet-aged gerbils. Hear. Res. 82:44-52, 1995.

Gratton MA, Schulte BA, Smythe NM. Quantification of the stria vascularis and strial capillary areas in quiet-reared young and aged gerbils. Hear. Res. 114:1-9, 1997.

Gundersen HJ, Jensen EB. The efficiency of systematic sampling in stereology and its prediction. J. Microsc. 147:229-263, 1987.

Gundersen HJ, Boysen M, Reith A. Comparison of semiautomatic digitizer-table and simple point counting performance in morphometry. Virchows Arch. 37:317-325, 1981.
Gundersen HJ, Jensen EB, Kieu K, Nielsen J. The efficiency of systematic sampling in stereology-reconsidered. J. Microsc. 193(3):199-211, 1999.

Hallpike CS, Cairns H. Observations on the pathology of Ménière's syndrome. J. Laryngol. Otol. 53:625-655, 1938.

Harris JP, KeITHLEY EM. A case against spiral ligament atrophy as a cause of Meniere's disease. ORL J. Otorhinolaryngol. Relat. Spec. 64:125-128, 2002.

Hequembourg S, Liberman MC. Spiral ligament pathology: a major aspect of age-related cochlear degeneration in C57BL/ 6 mice. J. Assoc. Res. Otolaryngol. 2(2):118-129, 2001.

Iснімiуa I, Suzuki M, Mogi G. Age-related changes in the murine cochlear lateral wall. Hear. Res. 139(1-2):116-122, 2000.

Ishiyama A, Agena J, Lopez I, TANg Y. Unbiased stereological quantification of neurons in the human spiral ganglion. Neurosci. Lett. 304:93-96, 2001.

IshiYama A, Lopez I, Ishiyama G, TANG Y. Unbiased quantification of the microdissected human Scarpa's ganglion neurons. Laryngoscope. 114(8):1496-1499, 2004.

Ishiyama G, Finn M, Lopez I, TANg $\mathrm{Y}$, Ishiyama A. Unbiased quantification of Scarpa's ganglion neurons in aminoglycoside ototoxicity. J. Vestibular Res. 15:197-202, 2005.

JoHnsson LF, HAwKINs JE. Vascular changes in the human ear associated with aging. Ann. Otol. Rhinol. Laryngol. 81:364-376, 1972.

Keithley EM, Harris B, Desai K, Linthicum F, Fischel-Ghodsian N. Mitochondrial cytochrome oxidase immunolabeling in aged human temporal bones. Hear. Res. 157(1-2):93-99, 2001.

Kikuchi T, Adams JC, Mirabe Y, So E, Kobayashi T. Potassium ion recycling pathway via gap junction systems in the mammalian cochlea and its interruption in the hereditary nonsyndromic deafness. Med. Electron Microsc. 33:51-56, 2000.

Kimura RA. Animal models of endolymphatic hydrops. Am. J. Otolaryngol. 3:447-451, 1982.

Kitahara M, Takeda T, Yazawa Y, Matsubara H, Kitano H. Experimental study on Ménière's disease. Otolaryngol. Head Neck Surg. 90(4):470-81, 1982.

Kusunoki T, Cureoglu S, Schachern PA, Baba K, Kariya S, Paparella MM. Age-related histopathologic changes in the human cochlea: a temporal bone study. Otolaryngol. Head Neck Surg. 131(6):897-903, 2004.

Kwok OT, NADOL JB. Correlation of otosclerotic foci and dengerative changes in the organ of Corti and spiral ganglion. Am. J. Otolaryngol. 10:1-12, 1989.

Lopez I, Ishiyama G, Tang Y, Frank M, Baloh RW, Ishiyama A. Estimation of the number of nerve fibers in the human vestibular endorgans using unbiased stereology and immunohistochemistry. J. Neurosci. Methods 145(1-2):37-46, 2005 a.

Lopez I, Ishiyama G, Tang Y, Tokita J, Baloh RW, Ishiyama A. Regional estimates of hair cells and supporting cells in the human crista ampullaris. J. Neurosci. Res. 82:421-431, 2005b.

Masutani H, TAKahashi H, SANDO I. Stria vascularis in Ménière's disease: a quantitative histopathological study. Auris, Nasus, Larynx 19(3):145-152, 1992.

Mathieu O, Cruz-Orive LM, Hoppller H, Weibel ER. Measuring error and sampling variation in stereology: comparison of the efficiency of various methods for planar image analysis. J. Microsc. 121:7588, 1981.

MAYHew TM, OlsEn DR. Magnetic resonance imaging (MRI) and model-free estimates of brain volume determined using the Cavalieri principle. J. Anat. 178:133-144, 1991.

MÉnIÈre P. Sur une forme de surdité grave dependant d'une lesion de l'oreille interne. Gaz. Med. (Paris) 16:29, 1861.

Merchant SN, Adams JC, Nadol JB Jr. Pathophysiology of Ménière's syndrome: are symptoms caused by endolymphatic hydrops? Otol. Neurotol. 26(1):74-81, 2005 Jan.

Nadol JB, Adams JC, Kim JR. Degenerative changes in the organ of Corti and lateral cochlear wall in experimental endolymphatic 
hydrops and human Ménière's disease. Acta Otolaryngol. (Stockh.) Suppl. 1519:47-49, 1995.

NeLson EG, HinOjOSA R. Presbycusis: a human temporal bone study of individuals with flat audiometric patterns of hearing loss using a new method to quantify stria vascularis volume. Laryngoscope 113(10):1672-1686, 2003.

Ohlemiller KK. Age-related hearing loss: the status of Schuknecht's typology. Curr. Opin. Otolaryngol. Head Neck Surg. 12:439443, 2004.

Ока Y. Stria vascularis width and thickness. Ear Res. Jpn. 15:66-67, 1984.

Pakkenberg B, Boesen J, Albeck M, GJerris F. Unbiased and efficient estimation of the total ventricular volume of the brain obtained from CT scan by a stereological method. Neuroradiology 31: 413-417, 1989.

Park JJ, Tang Y, Lopez I, Ishiyama A. Age-related change in the number of neurons in the human vestibular ganglion. J. Comp. Neurol. 431:437-443, 2001.

Pauler M, Schuknecht HF, White JA. Atrophy of the stria vascularis as a cause of sensorineural hearing loss. Laryngoscope 98:754-759, 1988.

Rauch SD, Merchant SN, Thedinger BA. Ménière's syndrome and endolymphatic hydrops: a double-blind temporal bone study. Ann. Otol. Rhinol. Laryngol. 98:873-883, 1989.

Reale E, Luciano L, Franke K, Pannese E, Wermbter G, Iurato S. Intercellular junctions in the vascular stria and spiral ligament. J. Ultrastruct. Res. 53:284-297, 1975.

SANTi PA, Lakhani BN. The effect of bumetanide on the stria vascularis: a stereological analysis of cell volume density. Hear. Res. 12(2):151-165, 1983.

SANTI PA, Muchow DC. Morphometry of the chinchilla organ of Corti and stria vascularis. J. Histochem. Cytochem. 27(11):1539 1542, 1979.

SAXEN A. Inner ear in presbycusis. Acta Otolaryngol. (Stockh.) 41:213-226, 1952.

SCHUKNECHT H. Pathology of the Ear. Lea and Febiger, Malvern, PA, 1993.
Schulte BA, Schmiedt RA. Lateral wall Na,K-ATPase and endocochlear potentials decline with age in quiet reared gerbils. Hear. Res. 61:35-46, 1992.

Shinomori Y, Kimura RS, Adams JC. Changes in immunostaining for $\mathrm{Na}^{+}, \mathrm{K}^{+}, 2 \mathrm{Cl}^{-}$cotransporter 1 , taurine, and c-Jun N-terminal kinase in experimentally induced endolymphatic hydrops. ARO Abstr. 24:134, 2001.

SPICER SS, SChulte BA. Differentiation of inner ear fibrocytes according to their ion transport related activity. Hear. Res. 56:53-64, 1991.

Sitcer SS, Schulte BA. The fine structure of spiral ligament cells relates to ion return to the stria and varies with place-frequency. Hear. Res. 100(1-2):80-100, 1996.

Sifcer SS, Schulte BA. Spiral ligament pathology in quiet-aged gerbils. Hear. Res. 172(1-2):172-85, 2002.

Spicer SS, Gratton MA, Schulte BA. Expression patterns of ion transport enzymes in spiral ligament fibrocytes change in relation to strial atrophy in the aged gerbil cochlea. Hear. Res. 111:93-102, 1997.

VASAma JP, Linthicum FH JR. Ménière's disease and endolymphatic hydrops without Ménière's symptoms: temporal bone histopathology. Acta Otolaryngol. 119(3):297-301, 1999.

VERNICK DM. The relationship of stria vascularis volume and cochlear duct volume. Am. J. Otolaryngol. 4(2):113-115, 1983.

Weber PC, Cunningham CD III, Schulte BA. Potassium recycling pathways in the human cochlea. Laryngoscope 111:1156-1165, 2001.

WeVER EG. Cross sections of the spiral ligament. In: Theory of Hearing. Dover Publications, New York, NY, 1949.

Wright CG, Schuknecht HF. Atrophy of the spiral ligament. Arch. Otolaryngol. 96:16-21, 1972.

YAMAKAWA K. Uber die apthologisch Veranderung bei einem MénièreKranken. J. Otorhinolaryngol. Soc. Jpn. 4:2310-2312, 1938.

Yazawa Y, Kitano H, Suzuki M, Tanaka H, Kitajima K. Studies of cochlear blood flow in guinea pigs with endolymphatic hydrops. ORL J. Otorhinolaryngol. Relat. Spec. 60(1):4-11, 1998. 